\title{
Prognostic impact of Skp2, ER and PGR in male and female patients with soft tissue sarcomas
}

\author{
Sveinung W Sorbye ${ }^{1,2^{*}}$, Thomas K Kilvaer ${ }^{2,4}$, Andrej Valkov ${ }^{1,2}$, Tom Donnem ${ }^{3,4}$, Eivind Smeland ${ }^{3}$, Khalid Al-Shibli ${ }^{2,5}$, \\ Roy M Bremnes ${ }^{3,4}$ and Lill-Tove Busund ${ }^{1,2}$
}

\begin{abstract}
Background: S-phase kinase-associated protein 2 (Skp2) is a member of mammalian F-box proteins. The purpose of this study is to clarify the prognostic significance of expression of Skp2 related to gender, estrogen receptor (ER) and progesterone receptor (PGR) in soft tissue sarcomas (STS). Skp2 has been demonstrated to display an oncogenic function since its overexpression has been observed in many human cancers. Optimized treatment of STS requires better identification of high-risk patients who will benefit from adjuvant therapy. The prognostic significance of Skp2 related to ER and PGR in STS has not been sufficiently investigated.
\end{abstract}

Methods: Tissue microarrays from 193 STS patients were constructed from duplicate cores of viable and representative neoplastic tumor areas. Immunohistochemistry was used to evaluate the expression of Skp2, ER and PGR.

Results: In univariate analyses, high tumor expression of Skp2 correlated $(p=0.050)$ with reduced disease-specific survival (DSS). In subgroup analyses expression of PGR in males $(p=0.010)$ and in patients older than 60 years $(p=0.043$ ) were negative prognostic factors for DSS. Expression of ER in females was a positive prognostic factor for DSS ( $p=0.041)$. In co-expression analyses in the whole cohort, low expression of Skp2 in combination with low expression of ER was positive for DSS ( $p=0.049)$. In females high expression of Skp2 in combination with low expression of ER was a negative prognosticator $(p=0.021)$. In the multivariate analyses, age $(p=0.012)$, malignancy grade $(p<0.001)$, wide resection margins $(P=0.010)$, ER negative / PGR positive co-expression profile $(p=0.002)$ and ER positive / PGR negative co-expression profile $(p=0.015)$ were independent negative prognostic factors for DSS. In females expression of Skp2 ( $p=0.006)$ was associated with shorter DSS.

Conclusions: We found diverse prognostic impacts of expression of Skp2, ER, PGR and DSS in male and female patients with STS. In men, but not women, ER positive / PGR negative co-expression profile was an independent negative prognostic factor for DSS. In women, but not men, high expression of Skp2 was associated with reduced DSS.

\section{Background}

S-phase kinase-associated protein 2 (Skp2), a mammalian F-box protein, displays S-phase-promoting function, through ubiquitin-mediated proteolysis of the CDK inhibitor p27. Skp2 has been shown to regulate cellular proliferation by targeting several cell cycle-regulated proteins for ubiquitination and degradation. Skp2 has also been demonstrated to display an oncogenic function since its overexpression has been observed in many human cancers [1]. High expression of Skp2 was reported to correlate with

\footnotetext{
* Correspondence: sveinung.sorbye@unn.no

'Department of Clinical Pathology, University Hospital of North Norway, Tromso, Norway

${ }^{2}$ Institute of Medical Biology, University of Tromso, Tromso, Norway

Full list of author information is available at the end of the article
}

reduced overall survival in patients with myxofibrosarcoma [2,3]. Di Vizio et al. [4] found that Skp2 expression correlates with poor prognosis in gastrointestinal stromal tumors (GIST). Oliveira found that Skp2 expression is associated with cell proliferation and a worse prognosis in 182 soft tissue sarcomas [5]. In a previous study we showed that high expression of Skp2 was a negative prognostic factor for DSS [6]. Interestingly, this correlation was statistically significant in females only, not in males. This may be related to differences in expression of sexual hormone receptors (ER and PGR) in male and female STS patients $[7,8]$. In previous studies, we have shown the prognostic value of female steroid hormone receptors in STSs, both alone and in coexpression with TGF- $\beta$, fascin and Akt isoforms [7-9]. Such prognostic impact is not surprising,

\section{Biomed Central}


since both ER and PGR regulate growth and cell differentiation upon ligand-dependent and ligand-independent activation and are in essence growth factors. However, the prognostic significance of Skp2 related to ER and PGR in STS has not been sufficiently investigated.

The purpose of this study is to clarify the prognostic significance of expression of Skp2 related to age, gender and female steroid hormone receptors (ER and PGR) in nongastrointestinal stromal tumor (non-GIST) STS. To achieve this, we analyzed the expression of these markers in 193 patients with non-GIST STS in relation to demographic and other clinicopathological variables. Our major hypothesis is that a different prognostic significance of Skp2 in men and women exists and is related to diverse gender expressions of ER and PGR.

\section{Methods}

Primary tumor tissues from patients diagnosed with STS at the University Hospital of North Norway (UNN) from 1973 to 2006 and the Hospitals of Arkhangelsk region,

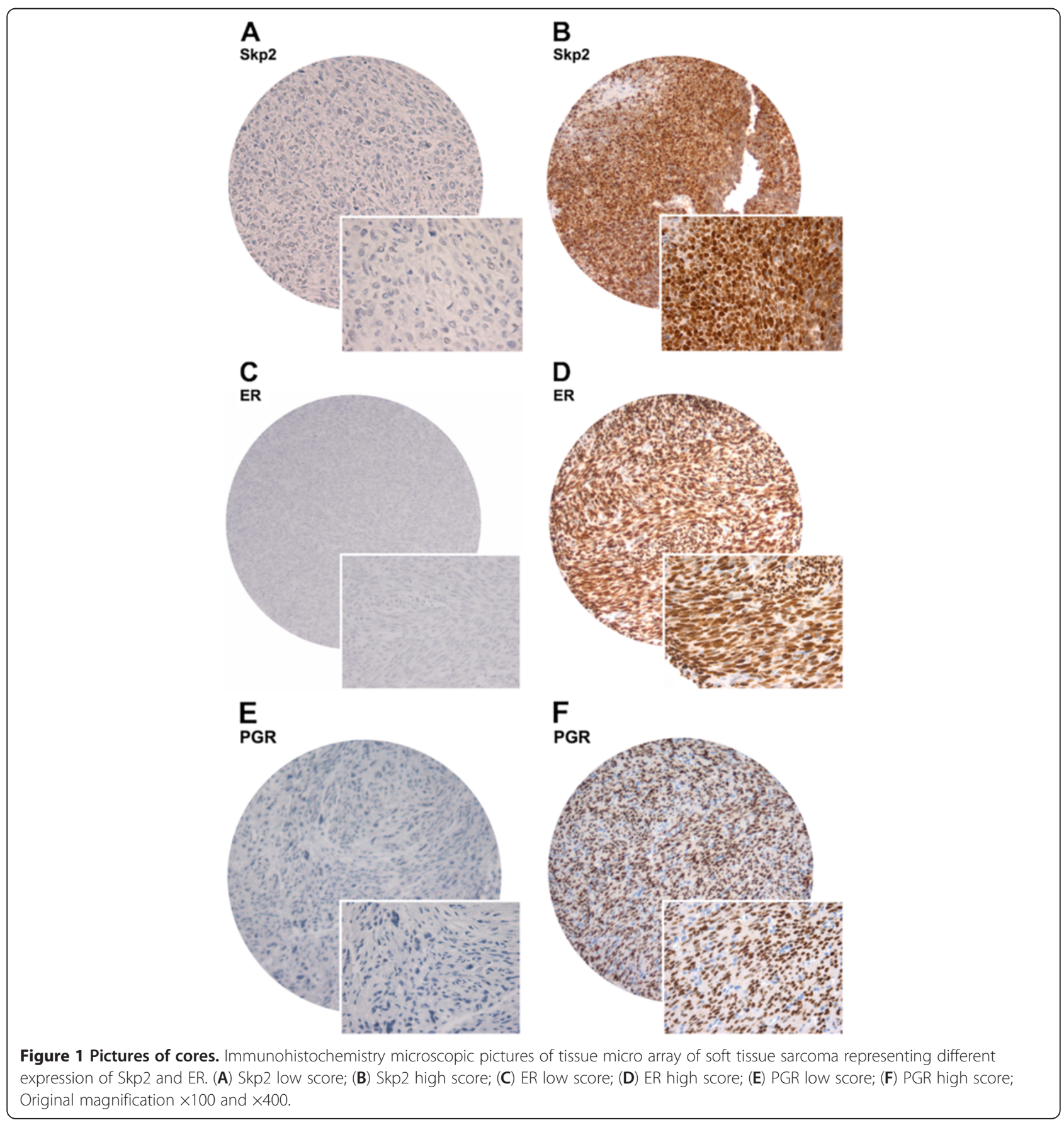


Table 1 Prognostic clinicopathological variables as predictors for disease-specific survival of soft tissue sarcomas (univariate analysis, log rank test), $\mathrm{N}=193$

\begin{tabular}{lcccc}
\hline Characteristic & $\begin{array}{c}\text { Patients } \\
\text { (n) }\end{array}$ & $\begin{array}{c}\text { Patients } \\
(\%)\end{array}$ & $\begin{array}{c}\text { Median } \\
\text { survival } \\
\text { (months) }\end{array}$ & $\begin{array}{c}5-\text { Year } \\
\text { survival } \\
(\%)\end{array}$ \\
\hline
\end{tabular}

\begin{tabular}{lccccc}
\hline Age & 17 & 9 & 190 & 47 & 0.064 \\
$<20$ years & 85 & 44 & 235 & 63 & \\
$20-59$ years & 91 & 47 & 111 & 51 & \\
$\geq 60$ years & & & & & \\
Gender & 81 & 42 & 235 & 60 & 0.087 \\
Male & 112 & 58 & 180 & 53 & \\
Female & & & & &
\end{tabular}

Nationality

Norwegian

Russian

Histology

Pleomorphic sarcoma

Leiomyosarcoma

Liposarcoma

MF/MFT

Angiosarcoma

Rhabdomyosarcoma

MPNST

Synovial sarcoma

Other STS

Tumor localization

Extremities
Trunk
Retroperitoneum
Head/Neck
Visceral
Tumor size
$<5 \mathrm{~cm}$
$5-9 \mathrm{~cm}$
$\geq 10 \mathrm{~cm}$
Missing
Malignancy grade
FNCLCC
1
2
3

Surgical margins

Wide

Non-wide

\begin{tabular}{|c|c|c|c|c|}
\hline 131 & 68 & 228 & 62 & 0.005 \\
\hline 62 & 32 & 81 & 44 & \\
\hline 57 & 30 & 52 & 45 & 0.031 \\
\hline 47 & 24 & 89 & 64 & \\
\hline 32 & 17 & NR & 71 & \\
\hline 16 & 8 & 123 & 56 & \\
\hline 8 & 4 & 10 & 38 & \\
\hline 9 & 5 & NR & 67 & \\
\hline 9 & 5 & NR & 56 & \\
\hline 12 & 6 & 31 & 30 & \\
\hline 3 & 2 & NR & - & \\
\hline 78 & 40 & 201 & 56 & 0.922 \\
\hline 37 & 19 & 214 & 53 & \\
\hline 27 & 14 & 135 & 51 & \\
\hline 13 & 7 & 191 & 58 & \\
\hline 38 & 20 & 202 & 62 & \\
\hline 57 & 30 & 257 & 69 & 0.026 \\
\hline 73 & 38 & 183 & 54 & \\
\hline 61 & 32 & 127 & 48 & \\
\hline 2 & 1 & & & \\
\hline
\end{tabular}

$\begin{array}{lllll}54 & 28 & \text { NR } & 81 & <0.001 \\ 76 & 39 & 80 & 55 & \\ 63 & 33 & 28 & 36 & \end{array}$

$\begin{array}{lllll}97 & 50 & 254 & 66 & <0.001\end{array}$

$\begin{array}{llll}96 & 50 & 128 & 46\end{array}$
Table 1 Prognostic clinicopathological variables as predictors for disease-specific survival of soft tissue sarcomas (univariate analysis, log rank test), $\mathbf{N}=193$ (Continued)

\begin{tabular}{lccccc}
\hline Chemotherapy & & & & & \\
No & 156 & 81 & 207 & 57 & 0.669 \\
Yes & 37 & 19 & 180 & 51 & \\
Radiotherapy & & & & & \\
No & 132 & 68 & 216 & 58 & 0.190 \\
Yes & 61 & 32 & 152 & 52 & \\
\hline
\end{tabular}

Abbreviations: MF/MFT, malignant fibroblastic/myofibroblastic tumors; MPNST, malignant peripheral nerve sheath tumor; STS, soft tissue sarcomas; NR, not reached; NOS, non specified.

Russia, were used in this retrospective study. In total, 496 potentially suitable patient records were identified from the hospitals' databases. Of these, 247 patients were excluded due to missing clinical data $(n=86)$ or inadequate material for histological examination $(\mathrm{n}=161)$. In addition, 33 were excluded because of metastasis at the time of the diagnosis, 13 were excluded because they had no surgery, and 10 patients had both metastasis and no surgery, leaving a total of 193 patients eligible for this study. This report includes data for 131 Norwegian patients and 62 Russian patients followed until September 2009. The median follow-up was 38 (range 0-392) months. Complete demographic and clinical data were collected retrospectively. Formalin-fixed and paraffinembedded tumor specimens were obtained from the archives of the Departments of Pathology at UNN and Arkhangelsk. The tumors were graded according to the French Fédération Nationales des Centres de Lutte Contre le Cancer (FNCLCC) system [WHO Tumors of Soft Tissue and bone, 2002]. Wide resection margins were defined as wide local resection with free microscopic margins or amputation of the affected limb or organ. Non-wide resection margins were defined as either marginal or intralesional resection margins.

\section{Microarray construction}

Two pathologists (AV and SWS) reviewed the histology of all soft tissue sarcoma cases. Tissue microarrays (TMAs) were constructed for high-throughput molecular pathology research [10]. The most representative areas of viable tumor cells were carefully selected and marked on the hematoxylin and eosin (HE) slides for the corresponding donor blocks and sampled for the tissue microarray collector blocks. The TMAs were assembled using a tissue-arraying instrument (Beecher Instruments).

Studies suggest that punching multiple $0.6 \mathrm{~mm}$ cores from different regions captures the heterogeneity of the tumors more accurately than a single 2 to $4 \mathrm{~mm}$ core [11]. We therefore chose to use two $0.6-\mathrm{mm}$ cores of 
Table 2 Percentage of high expression of ER, PGR and Skp2 in the different histological subtypes $N=193$

\begin{tabular}{lcccc}
\hline Histology & N & ER (\%)* & PGR (\%)** & Skp2 (\%)**** \\
\hline Pleomorphic sarcoma & 57 & 40 & 26 & 37 \\
Leiomyosarcoma & 47 & 50 & 43 & 40 \\
Liposarcoma & 32 & 35 & 23 & 21 \\
MF/MFT & 16 & 27 & 29 & 36 \\
Angiosarcoma & 8 & 25 & 13 & 29 \\
Rhabdomyosarcoma & 9 & 50 & 56 & 67 \\
MPNST & 9 & 11 & 11 & 44 \\
Synovial sarcoma & 12 & 40 & 27 & 50 \\
Other STS & 3 & 67 & 33 & 67 \\
Total & 193 & 39 & 30 & 38
\end{tabular}

* Chi 8.516, $p=0.385$.

** Chi 10.238, $p=0.249$.

*** Chi 8.596, $p=0.377$.

Abbreviations: MF/MFT, malignant fibroblastic/myofibroblastic tumors; MPNST, malignant peripheral nerve sheath tumor.

Chi-square test showed no differences in percentage of high expression of ER, PGR and Skp2 in the different histological subtypes.

viable neoplastic tissue. After reviewing all original sections of the tumor and taking heterogeneity into consideration, the two cores were selected to be as representative as possible (different areas). To include all core samples, 12 tissue array blocks were constructed. Multiple 4- $\mu \mathrm{m}$ sections were cut with a Micron microtome (HM355S) and stained with specific antibodies for immunohistochemistry (IHC).

\section{Immunohistochemistry (IHC)}

The applied antibodies were subjected to in-house validation by the manufacturer of IHC analysis on paraffinembedded material. All staining was performed in the Ventana Benchmark XT automated slide stainer (Ventana Medical System, Illkirch, France). Before staining, the sections were incubated over night at 60 degrees Celsius. Tissue sections were incubated with primary mouse monoclonal antibodies recognizing Skp2 (Zymed, catalog number 18-0307, 1:10), ER (Ventana, catalog number 790-4324, ready to use) and PGR (Ventana, catalog number 7904296). The incubation periods were 40 minutes for Skp2, 32 minutes for ER and $24 \mathrm{~min}$ for PGR. This was followed by application of liquid diaminobenzidine as substratechromogen, yielding a brown reaction product at the site of the target antigen (Ventana iView DAB Detection Kit, catalog number 760-091). iVIEW DAB Detection Kit is an indirect biotin streptavidin system for detecting mouse and rabbit primary antibodies. The DAB chromogen produces a dark brown precipitate that is readily visualized by light microscopy. All reagents are provided pre-diluted by the manufacturer for use in Ventana Benchmark XT. Finally, slides were counterstained with hematoxylin to visualize the nuclei. For each antibody, including negative controls, all TMA staining were performed in a single experiment. In the TMA we also used cores from carcinomas and normal tissue as positive and negative controls.

\section{Scoring of IHC}

The ARIOL imaging system (Genetix, San Jose, CA) was used to scan the slides for antibody staining of the TMAs. The specimens were scanned at a low resolution $(1.25 \times)$ and a high resolution $(20 \times)$ using an Olympus BX 61 microscope with an automated platform (Prior). The slides were loaded in the automated slide loader (Applied Imaging SL 50). Representative and viable tissue sections were scored manually on a computer screen semi-quantitatively for nuclear and/or cytoplasmic staining. The expression of Skp2, ER and PGR was scored as: 0 , negative; 1 , weak; 2 , intermediate and 3, strong (Figure 1). The score for each patient was based on the mean scoring of cores from one or several biopsies. To achieve maximal reproducibility in all cases, every staining was dichotomized (negative and positive expression). Positive expression was defined as mean score $>0$. All samples were anonymized and independently scored by two pathologists (AV and SWS). In case of disagreement, the slides were re-examined and the observers reached a consensus. When assessing a variable for a given score, the scores of the other variables and the outcome were hidden from the observers.

\section{Statistical methods}

All statistical analysis was performed using the statistical package SPSS (Chicago, IL), version 18. The IHC scores from each observer were compared for inter-observer reliability by use of a two-way random effects model with absolute agreement definition. The intra-class correlation coefficient (reliability coefficient) was obtained from these results.

Chi-square and Fisher exact tests were used to examine the association between molecular marker expression and various clinicopathological parameters. Univariate analyses were done using the Kaplan-Meier method, and statistical significance between survival curves was assessed by the $\log$ rank test. Disease-specific survival (DSS) was determined from the date of histologically confirmed STS diagnosis. Correlation of marker expression was done using the Pearson correlation (2-tailed) at the 0.05 and 0.01 levels.

Multivariate analysis was carried out using the Cox proportional hazards model to assess the specific impact of each pre-treatment variable on survival in the presence of other variables. Variables of significant value from the univariate analysis were entered into the Cox regression analysis. Probability for stepwise entry and removal was set at 0.05 and 0.10 , respectively. The significance level used was $\mathrm{p}<0.05$. 
Table 3 Expression of markers, gender and their prediction for disease-specific survival in patients with soft tissue sarcomas (univariate analysis; log-rank test), $\mathrm{All}=193$, Males $=81$, Females $=112$

\begin{tabular}{|c|c|c|c|c|c|}
\hline Marker expression & Patients (n) & Patients (\%) & Median survival (months) & 5-year survival (\%) & $\mathbf{P}$ \\
\hline \multicolumn{6}{|l|}{ Skp2, all } \\
\hline Low & 109 & 56 & NR & 63 & 0.050 \\
\hline High & 67 & 45 & 59 & 50 & \\
\hline Missing & 17 & 9 & & & \\
\hline \multicolumn{6}{|l|}{ Skp2, men } \\
\hline Low & 50 & 62 & NR & 63 & 0.577 \\
\hline High & 23 & 28 & 67 & 61 & \\
\hline Missing & 8 & 10 & & & \\
\hline \multicolumn{6}{|l|}{ Skp2, women } \\
\hline Low & 59 & 53 & NR & 63 & 0.066 \\
\hline High & 44 & 39 & 49 & 44 & \\
\hline Missing & 9 & 8 & & & \\
\hline \multicolumn{6}{|l|}{ ER, all } \\
\hline Low & 112 & 58 & 123 & 57 & 0.725 \\
\hline High & 72 & 67 & 91 & 57 & \\
\hline Missing & 9 & 5 & & & \\
\hline \multicolumn{6}{|l|}{ ER, men } \\
\hline Low & 49 & 60 & NR & 69 & 0.089 \\
\hline High & 29 & 36 & 58 & 49 & \\
\hline Missing & 3 & 4 & & & \\
\hline \multicolumn{6}{|l|}{ ER, women } \\
\hline Low & 63 & 56 & 57 & 47 & 0.041 \\
\hline High & 43 & 38 & NR & 62 & \\
\hline Missing & 6 & 5 & & & \\
\hline \multicolumn{6}{|l|}{ PGR, all } \\
\hline Low & 132 & 68 & NR & 62 & 0.101 \\
\hline High & 57 & 30 & 52 & 46 & \\
\hline Missing & 4 & 2 & & & \\
\hline \multicolumn{6}{|l|}{ PGR, men } \\
\hline Low & 64 & 79 & $N R$ & 69 & 0.010 \\
\hline High & 15 & 19 & 41 & 33 & \\
\hline Missing & 2 & 2 & & & \\
\hline \multicolumn{6}{|l|}{ PGR, women } \\
\hline Low & 68 & 61 & 80 & 55 & 0.832 \\
\hline High & 42 & 38 & 74 & 51 & \\
\hline Missing & 2 & 2 & & & \\
\hline
\end{tabular}

Abbreviations: NR, not reached.

\section{Consent}

The National Cancer Data Inspection Board and The Regional Committee for Research Ethics (REK nord) approved the study. The material was collected from our approved biobank for paraffin embedded material and slides. The Regional Committee approved that written consent from the patients for their information to be stored in the hospital database and used for research was not needed because most of the material was more than 10 years old, and most of the patients being dead. The ethics committee specifically waived the need for consent. Data were analyzed anonymously. 

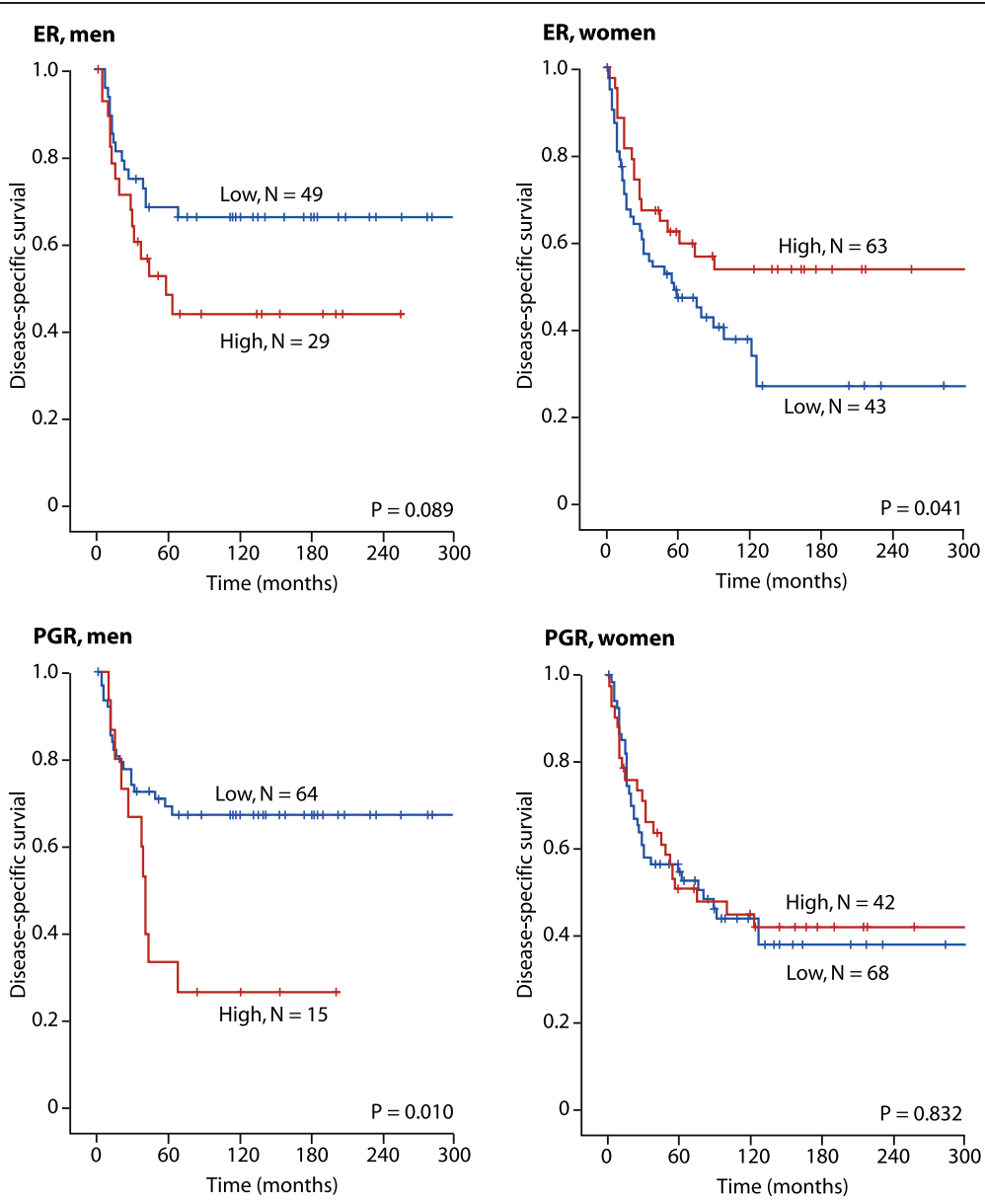

Figure 2 Survival plots ER and PGR. Disease-specific survival curves for high and low expression of ER and PGR in male $(N=81)$ and female $(\mathrm{N}=112)$ patients with soft tissue sarcomas.

\section{Results}

\section{Clinicopathological variables}

Demographic, clinical, and histopathological variables are shown in Table 1. Patient age ranged from 0-89 years (mean 55 years), and $42 \%$ of patients (81/193) were male. Treatment for all patients included surgery: 104 patients received surgery only; 52 patients received surgery and radiotherapy; 28 patients received surgery and chemotherapy; 9 patients received surgery, radiotherapy and chemotherapy. The 5-year survival for patients with wide and non-wide resection margins was $66 \%$ and $46 \%$ respectively, Table 1.

\section{Inter-observer variability}

There was good scoring agreement between the two investigating pathologists. The IHC scores from each observer were compared using a two-way random effects model with absolute agreement definition. The intra-class correlation coefficients (reliability coefficients, $r$ ) obtained from these results were 0.94 for Skp2 ( $\mathrm{p}<0.001), 0.92$ for ER $(\mathrm{p}<0.001)$ and 0.96 for PGR $(\mathrm{p}<0.001)$.

\section{Univariate analyses}

Nationality, histology, tumor size, malignancy grade and surgical margins were all significant indicators for diseasespecific survival (DSS) in univariate analyses (Table 1). Table 2 shows the percentage of high expression of ER, PGR and Skp2 in the different histological subtypes. Chisquare test showed no differences in overall expression of ER, PGR and Skp2 with respect to the different histological subtypes.

In univariate analyses, increased expression of Skp2 $(\mathrm{p}=0.050)$ correlated significantly with reduced DSS, (Table 3 and Figure 2). No such relationship was apparent for ER and PGR when males and females were combined in one group.

In subgroup analyses (Tables 3 and 4), increased PGR expression in men $(\mathrm{p}=0.010)$ and in patients older than 60 years $(\mathrm{p}=0.043)$ was associated with a reduced DSS. Increased ER expression in women was associated with longer DSS $(p=0.041)$. High expression of ER were associated with favorable survival in patients with rhabdomyosarcoma $(N=9, p=0.040)$. High expression of ER was 
Table 4 Expression of markers, age and their prediction for disease-specific survival in patients with soft tissue sarcomas (univariate analysis; log-rank test)

\begin{tabular}{|c|c|c|c|c|c|}
\hline Marker expression & Patients (n) & Patients (\%) & Median survival (months) & 5-Year survival (\%) & $\mathbf{P}$ \\
\hline \multicolumn{6}{|c|}{ Skp2, $<60$ years, $N=99$} \\
\hline Low & 52 & 53 & NR & 71 & \multirow[t]{3}{*}{0.074} \\
\hline High & 38 & 38 & 67 & 56 & \\
\hline Missing & 9 & 9 & & & \\
\hline \multicolumn{6}{|c|}{ Skp2, $\geq 60$ years, $N=94$} \\
\hline Low & 57 & 61 & 80 & 57 & \multirow[t]{3}{*}{0.188} \\
\hline High & 29 & 31 & 36 & 42 & \\
\hline Missing & 8 & 9 & & & \\
\hline \multicolumn{6}{|l|}{ ER, $<60$ years, $N=99$} \\
\hline Low & 55 & 56 & 127 & 59 & \multirow[t]{3}{*}{0.197} \\
\hline High & 40 & 40 & NR & 67 & \\
\hline Missing & 4 & 4 & & & \\
\hline \multicolumn{6}{|l|}{$E R, \geq 60$ years, $N=94$} \\
\hline Low & 57 & 61 & 80 & 55 & \multirow[t]{3}{*}{0.293} \\
\hline High & 32 & 34 & 52 & 44 & \\
\hline Missing & 5 & 5 & & & \\
\hline \multicolumn{6}{|c|}{ PGR, $<60$ years, $N=99$} \\
\hline Low & 63 & 64 & NR & 67 & \multirow[t]{3}{*}{0.488} \\
\hline High & 34 & 34 & NR & 55 & \\
\hline Missing & 2 & 2 & & & \\
\hline \multicolumn{6}{|c|}{ PGR, $\geq 60$ years, $N=94$} \\
\hline Low & 69 & 73 & 91 & 57 & \multirow[t]{3}{*}{0.043} \\
\hline High & 23 & 24 & 39 & 32 & \\
\hline Missing & 2 & 2 & & & \\
\hline
\end{tabular}

Abbreviations: NR, not reached.

associated with poor survival in patients with synovial sarcoma $(\mathrm{N}=12, \mathrm{p}=0.010)$. There were no significant differences in survival according to high or low expression of Skp2 in any of the histological subtypes (data not shown).

In patients with low expression of ER $(\mathrm{N}=112)$, men had better 5 -year survival $(69 \%)$ compared to women $(47 \%, \mathrm{p}=$ $0.002)$, while there were no differences $(p=0.376)$ between men and women in patients with high expression of ER (N $=72)$. In patients with low expression of PGR $(\mathrm{N}=132)$, men had better 5-year survival (69\%) compared to women $(55 \%, p=0.013)$, while there were no differences $(p=0.271)$ between men and women in patients with high expression of PGR $(N=57)$. There were no differences in survival between men and women in univariate analyses of patients with low $(\mathrm{N}=109, \mathrm{p}=0.529)$ or high $(\mathrm{N}=67, \mathrm{p}=0.233)$ expression of Skp2 (data not shown).

In co-expression analyses (Table 5) Skp2 negative / ER negative profile was associated with longer DSS $(p=0.049)$. In women a Skp2 positive and ER negative profile was associated with reduced DSS $(\mathrm{p}=0.021)$, Table 5 and Figure 3. In men a double negative ER/PGR profile was associated with longer DSS ( $\mathrm{p}=0.013$ ) while in women a double positive ER/PGR was associated with longer DSS ( $p=0.001)$. In patients younger than 60 years the combination ER negative and PGR positive was associated with shorter DSS. In the whole cohort of patients a triple positive expression of ER, PGR and Skp2 was associated with longer DSS ( $\mathrm{p}=$ 0.005), Figure 3. Triple negative expression of ER, PGR and Skp2 was also associated with longer DSS, but not statistically significant $(\mathrm{p}=0.068)$, Figure 3 . ER negative / PGR positive co-expression was associated with shorter DSS regardless of Skp2 expression, Table 6.

Taking into consideration the possible distortion of results by gender-related sarcomas (i.e. leiomyosarcoma in uterus) we have attempted to exclude these sarcomas and recalculate all analyses. There were no significant differences in the results compared to those obtained without exclusion of gender-related sarcomas (data not shown).

\section{Multivariate analyses}

Significant demographic, clinicopathological and expression variables from the univariate analyses were entered into the 
Table 5 Co-expression of Skp2/ER, Skp2/PGR and their prediction for disease-specific survival in patients with soft tissue sarcomas (univariate analysis; log-rank test), All = 193, Men = 81, Women = 112

\begin{tabular}{|c|c|c|c|c|c|}
\hline Co-expression & Patients (n) & Patients (\%) & Median survival (months) & 5-Year survival (\%) & $\mathbf{P}$ \\
\hline \multicolumn{6}{|l|}{ Skp2 / ER, all } \\
\hline Low/low & 66 & 34 & NR & 67 & \multirow[t]{5}{*}{0.049} \\
\hline Low/high & 39 & 20 & 91 & 59 & \\
\hline High/low & 35 & 18 & 57 & 44 & \\
\hline High/high & 30 & 16 & $N R$ & 58 & \\
\hline Missing & 23 & 12 & & & \\
\hline \multicolumn{6}{|l|}{ Skp2 / ER, men } \\
\hline Low/low & 33 & 41 & NR & 72 & \multirow[t]{5}{*}{0.427} \\
\hline Low/high & 16 & 20 & 37 & 50 & \\
\hline High/low & 11 & 14 & NR & 72 & \\
\hline High/high & 11 & 14 & 63 & 58 & \\
\hline Missing & 10 & 12 & & & \\
\hline \multicolumn{6}{|c|}{ Skp2 / ER, women } \\
\hline Low/low & 33 & 29 & 127 & 61 & \multirow[t]{5}{*}{0.021} \\
\hline Low/high & 23 & 21 & 91 & 65 & \\
\hline High/low & 24 & 21 & 31 & 32 & \\
\hline High/high & 19 & 17 & NR & 58 & \\
\hline Missing & 13 & 12 & & & \\
\hline \multicolumn{6}{|l|}{ Skp2 / PGR, all } \\
\hline Low/low & 80 & 41 & NR & 71 & \multirow[t]{5}{*}{0.056} \\
\hline Low/high & 25 & 13 & 54 & 46 & \\
\hline High/low & 40 & 21 & 59 & 49 & \\
\hline High/high & 27 & 14 & 67 & 51 & \\
\hline Missing & 21 & 11 & & & \\
\hline \multicolumn{6}{|c|}{ Skp2 / PGR, men } \\
\hline Low/low & 41 & 51 & NR & 73 & \multirow[t]{5}{*}{0.141} \\
\hline Low/high & 7 & 9 & 26 & 29 & \\
\hline High/low & 18 & 22 & NR & 61 & \\
\hline High/high & 5 & 6 & 67 & 60 & \\
\hline Missing & 10 & 12 & & & \\
\hline \multicolumn{6}{|c|}{ Skp2 / PGR, women } \\
\hline Low/low & 39 & 35 & NR & 68 & \multirow[t]{5}{*}{0.234} \\
\hline Low/high & 18 & 16 & 75 & 54 & \\
\hline High/low & 22 & 20 & 29 & 39 & \\
\hline High/high & 22 & 20 & 57 & 49 & \\
\hline Missing & 11 & 10 & & & \\
\hline
\end{tabular}

Abbreviations: NR, not reached.

multivariate Cox regression analysis (Table 7). In the multivariate analyses, age $(\mathrm{p}=0.012)$, malignancy grade $(\mathrm{p}<$ $0.001)$, wide resection margins $(\mathrm{p}=0.010)$, ER negative / PGR positive co-expression $(\mathrm{p}=0.002)$ and ER positive / PGR negative co-expression $(\mathrm{p}=0.015)$ were independent negative prognostic factors for DSS. In women, expression of Skp2 $(\mathrm{p}=0.006)$ was associated with reduced DSS. In women, tumor size $(p=0.020)$ and nationality $(p=0.014)$ were independent prognostic factors for DSS, Table 7. In multivariate analyses co-expression of Skp2/ER or Skp2/ PGR were not stronger prognosticators for DSS than single expression of Skp2, ER and PGR (data not shown). 

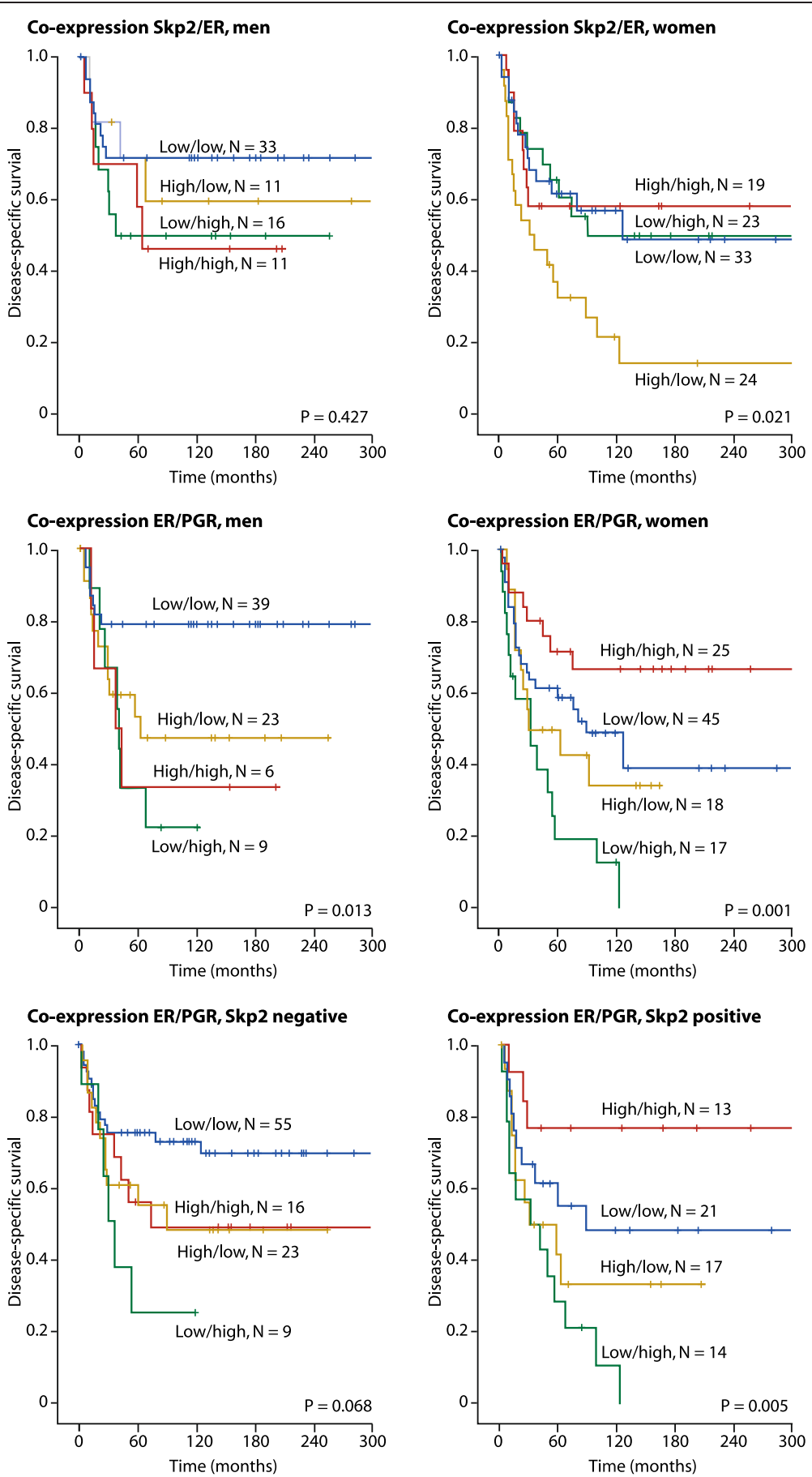

Figure 3 Survival plots co-expression. Disease-specific survival curves for co-expression of Skp2, ER or PGR in males $(N=81)$, females $(N=112)$ and co-expression of ER and PGR in Skp2 negative $(\mathrm{N}=109)$ and Skp2 positive $(\mathrm{N}=67)$ patients.

\section{Discussion}

In this large-scale study, we evaluated the prognostic significance of expression of Skp2 related to age, gender, ER and PGR in 193 STS patients. Our hypothesis was confirmed. We found diverse prognostic DSS impacts from gender related expression of Skp2, ER, PGR and DSS in STS. In men, but not women, an ER positive/
PGR negative co-expression profile was an independent negative prognostic factor for DSS. In women, but not men, high expression of Skp2 was associated with reduced DSS. High expression of ER reduced the negative impact of Skp2 in women. While women with the Skp2 positive / ER positive phenotype had favorable survival, women with the Skp2 positive / ER negative phenotype had 
Table 6 Co-expression of ER/PGR and their prediction for disease-specific survival in patients with soft tissue sarcomas (univariate analysis; log-rank test)

\begin{tabular}{|c|c|c|c|c|c|}
\hline Co-expression & Patients (n) & Patients (\%) & Median survival (months) & 5-year survival (\%) & $\mathbf{P}$ \\
\hline \multicolumn{6}{|c|}{ ER / PGR, all, N = 193} \\
\hline Low/low & 84 & 44 & NR & 69 & \multirow[t]{5}{*}{$<0.00$} \\
\hline Low/high & 26 & 13 & 38 & 24 & \\
\hline High/low & 41 & 21 & 62 & 52 & \\
\hline High/high & 31 & 16 & NR & 64 & \\
\hline Missing & 11 & 6 & & & \\
\hline \multicolumn{6}{|c|}{ ER / PGR, men, $N=81$} \\
\hline Low/low & 39 & 48 & NR & 79 & \multirow[t]{5}{*}{0.013} \\
\hline Low/high & 9 & 11 & 41 & 33 & \\
\hline High/low & 23 & 28 & 63 & 53 & \\
\hline High/high & 6 & 7 & 37 & 33 & \\
\hline Missing & 4 & 5 & & & \\
\hline \multicolumn{6}{|c|}{ ER / PGR, women, $N=121$} \\
\hline Low/low & 45 & 40 & 89 & 59 & \multirow[t]{5}{*}{0.001} \\
\hline Low/high & 17 & 15 & 31 & 19 & \\
\hline High/low & 18 & 16 & 29 & 50 & \\
\hline High/high & 25 & 22 & NR & 72 & \\
\hline Missing & 7 & 6 & & & \\
\hline \multicolumn{6}{|c|}{ ER / PGR, $<60$ years, N = 99} \\
\hline Low/low & 41 & 41 & NR & 72 & \multirow[t]{5}{*}{0.001} \\
\hline Low/high & 13 & 13 & 31 & 23 & \\
\hline High/low & 19 & 19 & NR & 58 & \\
\hline High/high & 21 & 21 & NR & 76 & \\
\hline Missing & 5 & 5 & & & \\
\hline \multicolumn{6}{|c|}{ ER / PGR, $\geq 60$ years, $N=94$} \\
\hline Low/low & 43 & 46 & NR & 64 & \multirow[t]{5}{*}{0.052} \\
\hline Low/high & 13 & 14 & 39 & 26 & \\
\hline High/low & 22 & 23 & 58 & 47 & \\
\hline High/high & 10 & 11 & 37 & 40 & \\
\hline Missing & 6 & 6 & & & \\
\hline \multicolumn{6}{|c|}{ ER / PGR, Skp2 low, N = 109} \\
\hline Low/low & 55 & 50 & NR & 76 & \multirow[t]{5}{*}{0.068} \\
\hline Low/high & 9 & 8 & 68 & 25 & \\
\hline High/low & 23 & 21 & 91 & 61 & \\
\hline High/high & 16 & 15 & 75 & 56 & \\
\hline Missing & 6 & 6 & & & \\
\hline \multicolumn{6}{|c|}{ ER / PGR, Skp2 high, N = 67} \\
\hline Low/low & 21 & 31 & 89 & 55 & \multirow[t]{5}{*}{0.005} \\
\hline Low/high & 14 & 21 & 31 & 29 & \\
\hline High/low & 17 & 25 & 29 & 42 & \\
\hline High/high & 13 & 19 & NR & 77 & \\
\hline Missing & 2 & 3 & & & \\
\hline
\end{tabular}

Abbreviations: NR, not reached. 
Table 7 Results of Cox regression analysis summarizing prognostic factors in patients with soft tissue sarcomas

\begin{tabular}{|c|c|c|c|c|c|c|c|c|c|}
\hline \multirow[b]{2}{*}{ Factor } & \multicolumn{3}{|c|}{ All patients, $\mathrm{N}=193$} & \multicolumn{3}{|c|}{ Men, $\mathbf{N}=81$} & \multicolumn{3}{|c|}{ Women, $\mathrm{N}=112$} \\
\hline & Hazard ratio & $95 \% \mathrm{Cl}$ & $\mathbf{P}$ & Hazard ratio & $95 \% \mathrm{Cl}$ & $\mathbf{P}$ & Hazard ratio & $95 \% \mathrm{Cl}$ & $\mathbf{P}$ \\
\hline \multicolumn{10}{|l|}{ Age } \\
\hline $0-59$ years & 1.00 & & & 1.00 & & & 1.00 & & \\
\hline$\geq 60$ years & 1.84 & $1.15-2.95$ & 0.012 & 1.69 & $0.65-4.41$ & 0.282 & 1.51 & $0.83-2.77$ & 0.179 \\
\hline \multicolumn{10}{|l|}{ Nationality } \\
\hline Norwegian & 1.00 & & & 1.00 & & & 1.00 & & \\
\hline Russian & 1.49 & $0.88-2.52$ & 0.143 & 1.39 & $0.41-4.66$ & 0.598 & 2.51 & $1.20-5.21$ & 0.014 \\
\hline \multicolumn{10}{|l|}{ Tumor size } \\
\hline$<5 \mathrm{~cm}$ & 1.00 & & $0.138^{*}$ & 1.00 & & $0.668^{*}$ & 1.00 & & $0.020^{*}$ \\
\hline $5-9 \mathrm{~cm}$ & 1.47 & $0.79-2.73$ & 0.226 & 1.68 & $0.54-5.25$ & 0.372 & 1.71 & $0.77-3.77$ & 0.187 \\
\hline$\geq 10 \mathrm{~cm}$ & 1.91 & $1.01-3.60$ & 0.047 & 1.32 & $0.40-4.39$ & 0.652 & 3.14 & $1.38-7.15$ & 0.006 \\
\hline \multicolumn{10}{|c|}{ Malignancy grade FNCLCC } \\
\hline 1 & 1.00 & & $<0.001^{*}$ & 1.00 & & $<0.001$ & 1.00 & & $0.004^{*}$ \\
\hline 2 & 2.72 & $1.36-5.46$ & 0.005 & 3.07 & $0.86-10.96$ & 0.084 & 4.33 & $1.76-10.67$ & 0.001 \\
\hline 3 & 4.61 & $2.26-9.40$ & $<0.001$ & 15.47 & $4.36-54.97$ & $<0.001$ & 4.23 & $1.64-10.89$ & 0.003 \\
\hline \multicolumn{10}{|c|}{ Resection margins } \\
\hline Wide & 1.00 & & & 1.00 & & & 1.00 & & \\
\hline Non-wide & 1.87 & $1.16-3.02$ & 0.010 & 7.69 & $2.67-22.16$ & $<0.001$ & 0.81 & $0.42-1.54$ & 0.512 \\
\hline \multicolumn{10}{|l|}{ Skp2 } \\
\hline Low & 1.00 & & & 1.00 & & & 1.00 & & \\
\hline High & 1.48 & $0.87-2.52$ & 0.151 & 0.46 & $0.19-1.12$ & 0.088 & 2.52 & $1.31-4.85$ & 0.006 \\
\hline \multicolumn{10}{|l|}{ ER / PGR } \\
\hline Low/low & 1.00 & & $0.006^{*}$ & 1.00 & & $0.004^{*}$ & 1.00 & & $0.216^{*}$ \\
\hline Low/high & 2.64 & $1.43-4.85$ & 0.002 & 4.99 & $1.31-18.97$ & 0.018 & 1.91 & $0.89-4.11$ & 0.097 \\
\hline High/low & 2.07 & $1.15-3.73$ & 0.015 & 8.35 & $2.55-27.36$ & $<0.001$ & 1.76 & $0.79-3.93$ & 0.170 \\
\hline High/high & 1.16 & $0.57-2.38$ & 0.682 & 4.50 & $0.96-21.13$ & 0.056 & 0.92 & $0.36-2.35$ & 0.868 \\
\hline
\end{tabular}

poor survival. To the best of our knowledge, this is the first prognostic evaluation of Skp2 related to the female hormone receptors ER and PGR in STS.

Expression of ER and PGR is a routinely investigated indicator of endocrine therapy success in breast cancer [12,13] and a modest, but significantly better overall survival of antiestrogen receptor therapy has been documented [14]. ER and PGR are also reported to be positive prognosticators of uterine leiomyosarcomas [15]. However, extra-uterine sarcomas have barely been explored in this context. The distribution and prognostic value of expression of these steroid hormone receptors in STS are therefore of great scientific interest. In our study, in the univariate analyses, ER showed a significantly favorable influence on survival in female patients, but not in males. PGR was an unfavorable prognosticator for men, but not for women. In multivariate analysis ER positive / PGR negative co-expression is an independent negative prognostic factor for DSS in males, but not in females.

We have modified the Allred score for STS and used 1\% positivity as cut-off value $[7,16]$. The strong and moderate (score 3 and 2, respectively) hormone receptor expression occurred mostly in sarcomas of uterus, pelvis and breast, while the weak (score 1) expression of both ER and PGR was surprisingly evenly distributed among location, gender and age. Generally, 39\% of the tumors expressed ER and $30 \%$ expressed PGR in our material. Roughly half of the patients expressed at least one of these receptors. The findings are in partial agreement with findings of Chaudhuri et al. [17] who found ER to be positive in $24 \%$ of STS.

Huang et al. suggested that the therapeutic strategies designed to reduce Skp2 may play an important clinical role in treatment of breast cancer cells, especially ER/ HER2 negative breast cancers [18]. Voduc et al. found 
cyclin E and Skp2 to be prognostic for breast cancerspecific survival in univariate analyses. Double positive expression of cyclin E / Skp2 was associated with young age at diagnosis, grade 3 tumors, ER-negative status and HER2 negative status [19]. Zheng et al. found that higher levels of Skp2 were detected more frequently in ER-negative breast cancer tumors and tumors metastatic to the axillary lymph nodes [20]. Signoretti et al. also found that higher levels of Skp2 are present more frequently in ER-negative tumors than in ER-positive cases. The subset of Skp2 positive / ER negative breast carcinomas were also characterized by high tumor grade and HER2 negative [21]. In our material, the five year DSS in Skp2 positive / ER negative women with STS was $32 \%$ compared to $58 \%$ in Skp2 positive / ER positive women $(\mathrm{P}=0.021)$.

In our previous work we have shown that ER and PGR expression possess variable prognostic significance depending on gender, both per se and in coexpression with TGF- $\beta$, fascin and Akt isoforms [7-9]. In the present study, the prognostic diversity of Skp2, ER and PGR in men and women was seen in the different co-expression profiles: female patients with Skp2 positive / ER negative profile had decreased survival rates. For men, the Skp2 negative / ER negative profile was the most favorable phenotype. PGR expression in men, but not women, was associated with a shorter DSS. ER expression in women, but not men, was associated with a longer DSS. The ER negative / PGR positive profile was a significantly unfavorable factor for the whole patient cohort both in univariate and multivariate analysis. Interestingly, such a profile occurred in only $2 \%$ of patients in one large-scale study based on 3000 breast cancer cases [22], while in our STS study this profile was seen in $13 \%$ of tumors.

The data collection introduced problems in identifying adequate numbers of similar patients with similar tumors and with the same treatment traditions. These are well known problems when conducting STS studies. Our findings are in large hypothesis generating, and to be more conclusive future STS studies must be based on large, multi-institutional and multinational studies with possibilities to establish adequately sized STS patient cohorts of homogenous tumor groups. However, all tumors investigated herein had mesenchymal derivation and belong to the same generic group.

\section{Conclusions}

In conclusion, there were different prognostic impacts of expression of Skp2, ER, PGR and DSS in male and female patients with STS. In men, but not in women, ER positive / PGR negative co-expression was an independent negative prognostic factor for DSS. In women, but not in men, expression of Skp2 was associated with reduced DSS.

\section{Competing interests}

The authors declare that they have no competing interests.

\section{Authors' contributions}

SWS, TK, AV, TD, RMB and LTB participated in the design of the study. TK, ES and AV collected clinical information. SWS and AV reviewed all the histological diagnosis, histological grading, selected and marked the slides for TMA construction. SWS, TK and AV performed the experiments. SWS, TK, AV, TD, RMB and LTB performed the statistical analysis. SWS, TK, AV, TD, ES, KAS and LTB contributed reagents/materials/analysis tools. SWS, TD, ES, KAS, RMB and LTB drafted the manuscript. All authors read and approved the final manuscript.

\section{Acknowledgments}

This study was funded by the Helse Nord, The Norwegian Childhood Cancer Network, The Norwegian Sarcoma Group and The Norwegian Cancer Society. The funders had no role in study design, data collection and analysis, decision to publish, or preparation of the manuscript. We are grateful to Frode Skjold for establishing functional connections between the databases and Magnus L. Persson for making the TMA blocks.

\section{Author details}

${ }^{1}$ Department of Clinical Pathology, University Hospital of North Norway, Tromso, Norway. ${ }^{2}$ Institute of Medical Biology, University of Tromso, Tromso, Norway. ${ }^{3}$ Department of Oncology, University Hospital of North Norway, Tromso, Norway. ${ }^{4}$ Institute of Clinical Medicine, University of Tromso, Tromso, Norway. ${ }^{5}$ Department of Pathology, Nordland Central Hospital, Bodo, Norway.

Received: 22 October 2012 Accepted: 8 March 2013 Published: 15 March 2013

\section{References}

1. Wang G, Chan CH, Gao Y, Lin HK: Novel roles of Skp2 E3 ligase in cellular senescence, cancer progression, and metastasis. Chin J Cancer 2012 31:169-177.

2. Huang HY, Kang HY, Li CF, Eng HL, Chou SC, Lin CN, et al: Skp2 overexpression is highly representative of intrinsic biological aggressiveness and independently associated with poor prognosis in primary localized myxofibrosarcomas. Clin Cancer Res 2006, 12:487-498.

3. Huang HY, Huang WW, Wu JM, Huang CK, Wang JW, Eng HL, et al: Flow cytometric analysis of DNA ploidy and S-phase fraction in primary localized myxofibrosarcoma: correlations with clinicopathological factors, Skp2 expression, and patient survival. Ann Surg Oncol 2008, 15:2239-2249.

4. Di VD, Demichelis F, Simonetti S, Pettinato G, Terracciano L, Tornillo L, et al: Skp2 expression is associated with high risk and elevated Ki67 expression in gastrointestinal stromal tumours. BMC Cancer 2008, 8:134.

5. Oliveira AM, Okuno SH, Nascimento AG, Lloyd RV: Skp2 protein expression in soft tissue sarcomas. J Clin Oncol 2003, 21:722-727.

6. Sorbye SW, Kilvaer TK, Valkov A, Donnem T, Smeland E, AI-Shibli K, et al: Prognostic impact of Jab1, p16, p21, p62, Ki67 and Skp2 in soft tissue sarcomas. PLOS One 2012, 7:e47068.

7. Valkov A, Sorbye S, Kilvaer TK, Donnem T, Smeland E, Bremnes RM, et al: Estrogen receptor and progesterone receptor are prognostic factors in soft tissue sarcomas. Int J Oncol 2011, 38:1031-1040.

8. Valkov A, Kilvaer TK, Sorbye SW, Donnem T, Smeland E, Bremnes RM, et al: The prognostic impact of Akt isoforms, PI3K and PTEN related to female steroid hormone receptors in soft tissue sarcomas. J Transl Med 2011, 9:200.

9. Valkov A, Sorbye SW, Kilvaer TK, Donnem T, Smeland E, Bremnes RM, et al: The prognostic impact of TGF-beta1, fascin, NF-kappaB and PKC-zeta expression in soft tissue sarcomas. PLoS One 2011, 6:e17507.

10. Nocito A, Kononen J, Kallioniemi OP, Sauter G: Tissue microarrays (TMAs) for high-throughput molecular pathology research. Int J Cancer 2001, 94:1-5.

11. Kallioniemi OP, Wagner U, Kononen J, Sauter G: Tissue microarray technology for high-throughput molecular profiling of cancer. Hum Mol Genet 2001, 10:657-662.

12. Fisher B, Redmond C, Brown A, Wolmark N, Wittliff J, Fisher ER, et al: Treatment of primary breast cancer with chemotherapy and tamoxifen. N Engl J Med 1981, 305:1-6. 
13. Fisher B, Redmond C, Brown A, Wickerham DL, Wolmark N, Allegra J, et al: Influence of tumor estrogen and progesterone receptor levels on the response to tamoxifen and chemotherapy in primary breast cancer. J Clin Oncol 1983, 1:227-241.

14. Knight WA, Livingston RB, Gregory EJ, McGuire WL: Estrogen receptor as an independent prognostic factor for early recurrence in breast cancer. Cancer Res 1977, 37:4669-4671.

15. Kelley TW, Borden EC, Goldblum JR: Estrogen and progesterone receptor expression in uterine and extrauterine leiomyosarcomas: an immunohistochemical study. Appl Immunohistochem Mol Morphol 2004, 12:338-341.

16. Harvey JM, Clark GM, Osborne CK, Allred DC: Estrogen receptor status by immunohistochemistry is superior to the ligand-binding assay for predicting response to adjuvant endocrine therapy in breast cancer. J Clin Oncol 1999, 17:1474-1481.

17. Chaudhuri PK, Walker MJ, Beattie CW, Das Gupta TK: Distribution of steroid hormone receptors in human soft tissue sarcomas. Surgery 1981, 90:149-153.

18. Huang HC, Lin CL, Lin JK: 1,2,3,4,6-penta-O-galloyl-beta-D-glucose, quercetin, curcumin and lycopene induce cell-cycle arrest in MDA-MB-231 and BT474 cells through downregulation of Skp2 protein. J Agric Food Chem 2011, 59:6765-6775.

19. Voduc D, Nielsen TO, Cheang MC, Foulkes WD: The combination of high cyclin E and Skp2 expression in breast cancer is associated with a poor prognosis and the basal phenotype. Hum Pathol 2008, 39:1431-1437.

20. Zheng WQ, Zheng JM, Ma R, Meng FF, Ni CR: Relationship between levels of Skp2 and P27 in breast carcinomas and possible role of Skp2 as targeted therapy. Steroids 2005, 70:770-774.

21. Signoretti S, Di ML, Richardson A, Ramaswamy S, Isaac B, Rue M, et al: Oncogenic role of the ubiquitin ligase subunit Skp2 in human breast cancer. J Clin Invest 2002, 110:633-641.

22. Bernoux A, de Cremoux P, Laine-Bidron C, Martin EC, Asselain B, Magdelenat $\mathrm{H}$ : Estrogen receptor negative and progesterone receptor positive primary breast cancer: pathological characteristics and clinical outcome. Institut Curie Breast Cancer Study Group. Breast Cancer Res Treat 1998, 49:219-225.

doi:10.1186/1472-6890-13-9

Cite this article as: Sorbye et al:: Prognostic impact of Skp2, ER and PGR in male and female patients with soft tissue sarcomas. BMC Clinical Pathology 2013 13:9.

\section{Submit your next manuscript to BioMed Central and take full advantage of:}

- Convenient online submission

- Thorough peer review

- No space constraints or color figure charges

- Immediate publication on acceptance

- Inclusion in PubMed, CAS, Scopus and Google Scholar

- Research which is freely available for redistribution 